\title{
POSSIBLE EGGSAC DEFENSE BEHAVIORS IN THE SPIDER ULOBORUS GLOMOSUS (ARANEAE: ULOBORIDAE)*
}

\author{
By Paula E. Cushing \\ Biology Department \\ Virginia Polytechnic Institute and State University, \\ Blacksburg, Virginia 24061
}

\section{INTRODUCTION}

Adult female Uloborus glomosus (Walckenaer) (Uloboridae) deposit their stellate eggsacs in a chain that grows inward along a radius from the perimeter of their horizontal orb-webs. Spiderlings emerge first from the most peripheral eggsac such that late in the reproductive season a female may tend a chain of several eggsacs, the outermost (oldest) two or three of which are vacant. Adult females without eggsacs often show active responses to disturbance (jumping from the web, shaking the web, or moving to the edge of the web), whereas those with eggsac chains in their webs remain aligned with their eggsacs throughout the day and remain in position next to the eggsacs when disturbed (Opell and Eberhard 1984, Cushing and Opell in press; Fig. 1). Cushing (1988) suggests that the stick-like appearance of a female aligned with an eggsac chain may protect a female from visually hunting predators. However, this tending behavior also places the female in a position to guard her eggsacs by warding off egg predators and parasitoids. The purpose of this study is to determine if, while tending eggsacs, female U. glomosus exhibit unique behaviors that actively deter egg parasitoids and predators.

Uloboridae eggsacs are known to host three genera of hymenopteran parasitoids and predators: Idris (Scelionidae), Eurytoma (Eurytomidae), and Arachnopteromalus (Pteromalidae) (Austin 1985). Arachnopteromalus dasys Gordh was originally collected from the eggsacs of the uloborid Octonoba sinensis (Simon) $(=$ Uloborus octonarius Muma) (Gordh 1976). I have since collected this species from the eggsacs of $U$. glomosus in Montgomery County, Virginia (Fig. 2). Therefore, the potential exists for the development of behavioral adaptations against eggsac parasitism.

*Manuscript received by the editor October 8, 1989. 
Hoffmaster (1982) described eggsac defense behaviors among female Philoponella (=Uloborus) republicana. When disturbed, these spiders moved to the edge of the web, taking the eggsac with them. This was possible because their single, lenticular eggsacs are suspended from, but not anchored into, the web as are those of $U$. glomosus. Females with eggsacs did not respond to hummingbird (Trochilidae) attacks whereas those without eggsacs did. Hoffmaster suggests that these behavioral differences between females with and those without eggsacs permit the spider to protect its parental investment.

Such eggsac tending behavior is also common among wandering spiders in the families Lycosidae, Pisauridae, Salticidae, Thomisidae, Gnaphosidae, Clubionidae, and Oxyopidae (Eberhard 1974, Matlack and Jennings 1977, Gertsch 1979, Fink 1987, Austin 1988). Austin (1988) found that the brooding behavior of female Clubiona robusta L. Koch (Clubionidae) increased the survival of eggs and spiderlings, protecting them from predation by ants and other predators. Although eggsac tending is most common among wandering spiders, it is also exhibited by the web builders Agelenidae (Kaston 1948) and Uloboridae (Patel and Bradoo 1981, Hoffmaster 1982).

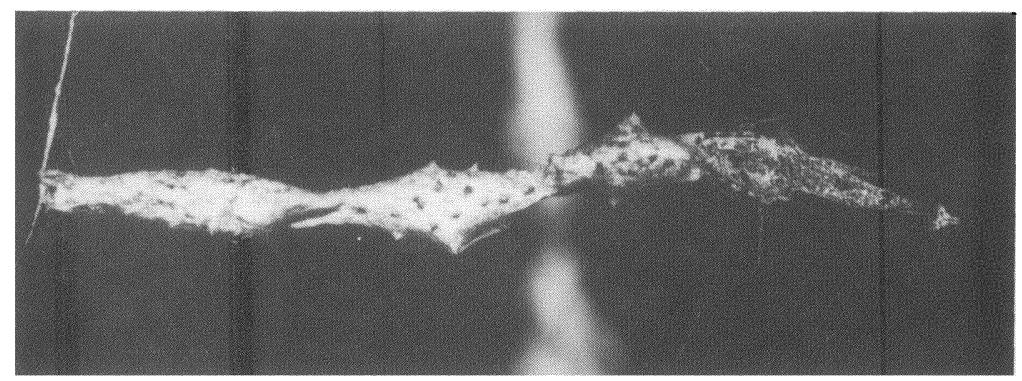

Fig. 1. An adult female $U$. glomosus (right) aligned with her eggsac chain. Scale bar $=5 \mathrm{~mm}$.

\section{Materials AND Methods}

Twenty adult female $U$. glomosus with eggsac chains consisting of two to six eggsacs, at least two of which were unhatched, were collected from shrubbery on the V. P. I. and S. U. campus in midJuly, 1987. Each spider was allowed to build webs on a horizontal $10 \times 10 \mathrm{~cm}$ wooden frame set inside $10 \times 10 \times 9 \mathrm{~cm}$ plastic freezer containers covered with plastic saran wrap and maintained on a 
14:10 light:dark cycle. The females incorporated their eggsac chains into these new webs. Females were fed and watered regularly and monitored every day to detect the emergence of the small $(2.5 \mathrm{~mm}$ long) parasitoid wasps, Arachnopteromalus dasys. When the wasps emerged they were individually placed in small plastic Petri dishes containing a piece of cotton moistened with dilute honey.

To determine if the female spiders exhibited protective behaviors against these eggsac parasitoids, I used a small brush to place a randomly chosen one to five day old wasp onto the eggsac furthest from each female (the oldest eggsac), being careful not to touch the eggsacs. I then recorded: 1) the time it took a female to respond to the presence of the wasp, 2) the first response of the female, 3) the eggsac on which the wasp was found when the female first responded to it, and 4) any subsequent behaviors that occurred up to 5 minutes after wasp placement. None of the females responded during wasp placement onto the eggsacs indicating that the transfer procedure itself did not disturb the spider. Super $8 \mathrm{~mm}$ movies taken of four females' responses to the presence of $A$. dasys on their eggsacs were used to analyze the behaviors.

This experiment was repeated using second and third instar $U$. glomosus spiderlings instead of wasps. I chose spiderlings closest in size to the parasitic wasps. Eleven of the original 20 females were tested; the remainder had since died.

\section{RESULTS}

Five to 16 wasps $($ mean $=9.3)$ emerged from eggsacs of three of the 20 spiders collected. No spiderlings hatched from these parasitized eggsacs. However, parasitic wasps may have emerged from some eggsacs of a chain before I collected them. Therefore, these observations do not yield unequivocal estimates of parasitism rates.

The most common initial response to wasps shown by the spiders was a jerking behavior. Sixteen females (80\%) jerked the web in response to the wasp's presence. They responded from two seconds to 4 minutes, 10 seconds (mean $=39$ seconds, s.d. $=62.07$ seconds) after the wasp was placed on the eggsac chain. Two spiders (10\%) showed no response throughout the five minute trial. One spider touched the closest (most recently produced) eggsac with its abdomen 20 seconds after wasp placement. One female turned and walked along the eggsac chain one minute, 20 seconds after the wasp 

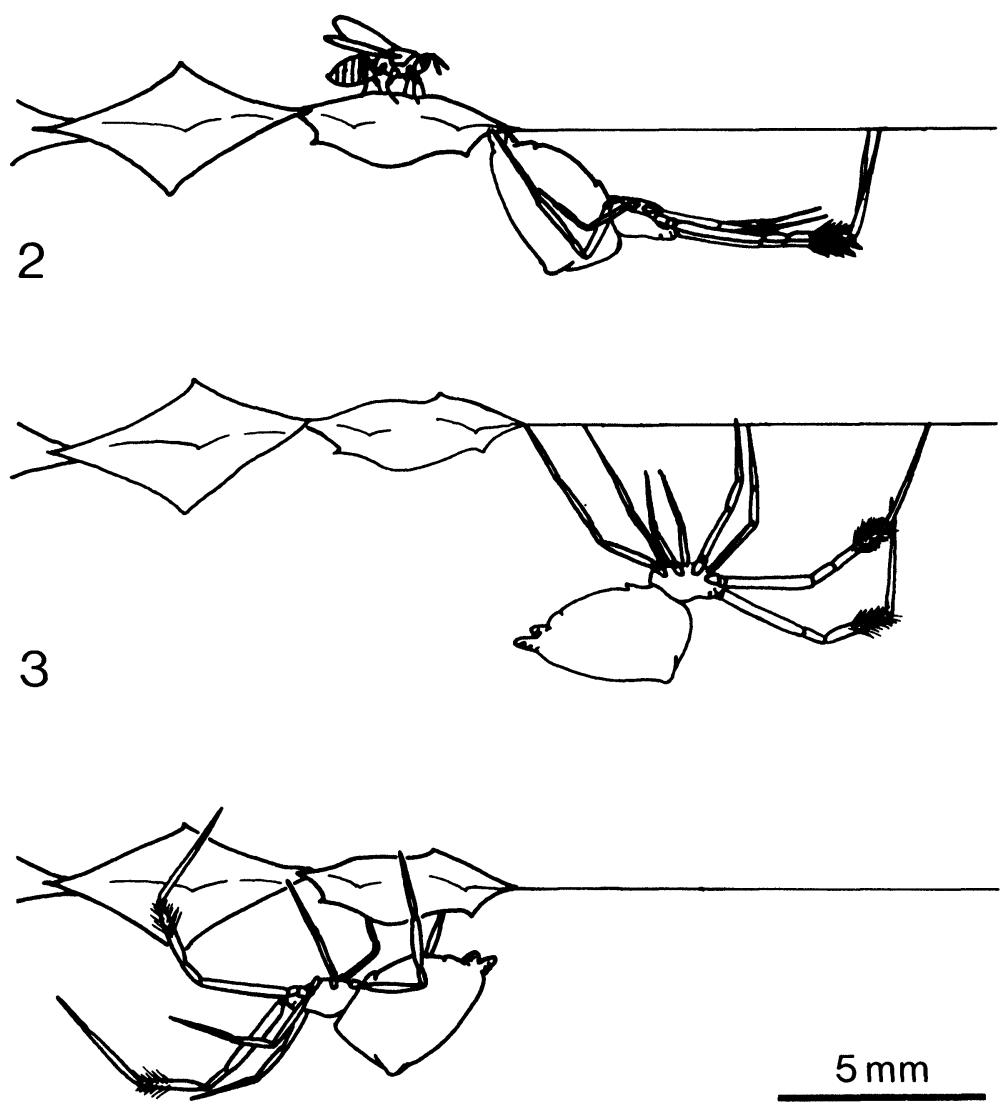

4

Figs. 2-4. 2. Parasitoid wasp A. dasys resting on a $U$. glomosus eggsac. 3. The stilting posture during web jerking. 4. Leg sweeping behavior.

was placed on the furthest eggsac. There was an average of four eggsacs in a chain (s.d. $=1.6)$ and an average of only two eggsacs (s.d. $=1.3$ ) between the spider and the wasp when the female responded to the wasp's presence. For all but one of the spiders, the wasp was either on a potentially viable (unhatched) eggsac or there were viable eggsacs between the female and the wasp when the female responded. 
Of the three spiders from whose eggsacs wasps emerged: one jerked the web 21 seconds after the wasp was placed on the furthest (the fifth) eggsac; one jerked the web one minute after the wasp was placed on the furthest (the fourth) eggsac, at which time the wasp was on the eggsac next to the female; and one jerked the web four seconds after the wasp was placed on the furthest (the sixth) eggsac, and then turned and walked along the eggsac chain.

Super 8 films showed that this jerking response is not stimulated by direct contact. A female was typically aligned with her eggsac chain in the posture shown in Fig. 1. The 4th pair of legs or the abdomen touched the most recently constructed eggsac and probably detected the wasp's movement on the eggsacs. The jerking response had two distinct elements: the female flexed all four pairs of legs at the tibia-metatarsus joints, thus raising her body toward the web; she then rapidly extended the legs at these joints (Fig. 3). This stilting behavior lowered the spider's body from the web surface and caused the whole web to oscillate sharply. This jerking behavior was a single event with pauses between occurrences (mean $=14.2$ seconds, s.d. $=13.3$ ).

After initially responding to the wasps' presence by jerking the web, 13 females $(65 \%)$ subsequently jerked the web one to seven more times (mean $=3.1)$; one of these moved to the edge of the web after jerking the web a second time. The female that initially touched the closest eggsac with her abdomen subsequently jerked the web once. The second type of response of 12 spiders $(60 \%)$ was to turn and walk along the eggsac chain. The female that showed this latter behavior as an initial response subsequently jerked the web.

The Super 8 films of this second type of behavior show that spiders first turned and faced the nearest (most recently made) eggsac and began walking along the chain. Sometimes, while walking, a spider paused and jerked the web. As they walked, the spiders extended their long front legs around the sides of the eggsac chain, touching and sweeping the surfaces of the eggsacs with the tarsi (Fig. 4). Neither during the jerking behavior nor during the leg sweeping did this behavior dislodge a wasp from the eggsacs. However, when the spiders jerked the web, the wasps crouched down and lowered their antennae.

A lower percentage of the 11 surviving females tested with spiderlings rather than wasps showed the behaviors described above. Five 
of the adults (45\%) initially jerked their webs from 2 seconds to 3 minutes, 40 seconds (mean $=64.5$ seconds, s.d. $=92.1$ ) after the spiderling was placed on the eggsac chain. Five (45\%) showed no response throughout the 5 minute trial, and one turned and faced its eggsacs. The five females that initially jerked their webs showed this behavior two to nine more times (mean $=4.2$ ). Three of these also turned and faced their eggsac chains. None of the females walked along their eggsac chains as they did in the wasp trials. Although the percentage of females responding to spiderlings on their eggsacs was less than the percentage responding to wasps on their eggsacs, this was not significant $\left(\mathrm{X}^{2}=1.536, \mathrm{p}>0.1\right)$. There was also no significant difference between the mean initial response time of females tested with wasps and those tested with spiderlings $(t=0.756$, $\mathrm{p}>0.4)$.

\section{Discussion}

Most female $U$. glomosus exhibited previously undescribed webjerking and leg sweeping behaviors in response to parasitoid wasps and spiderlings crawling on their eggsacs. Since none of the wasps observed in this study were dislodged when the spider jerked the web, it would seem, at first, that this behavior is not a very effective response against eggsac parasitism. However, it may prevent the wasps from inserting their ovipositors in the eggsacs. In fact, none of the wasps used in this study attempted to oviposit. However, all the wasps were separated soon after emergence and may not have attempted to oviposit because they were virgins. As all three of the females from whose eggsacs the wasps emerged showed the jerking response, it is unclear just how effective the jerking response is, although it takes only one fertile wasp to do a great deal of damage to an eggsac chain.

The fact that females jerked their webs in response to spiderlings crawling over the eggsacs suggests that females cannot distinguish between parasitoids and progeny crawling along their eggsacs. In other words, they do not respond to stimuli produced only by hymenopteran parasitoids (i.e., $A$. dasys). Instead, they respond to stimuli produced by anything crawling on the eggsac chain.

Female $U$. glomosus with eggsac chains show a strong tendency to remain aligned with those eggsacs even when disturbed (Cushing and Opell in press). This study indicates that this tendency not only 
makes a female more cryptic but may also enable her to protect her eggsacs from parasitoids, although further experimentation using fertile wasps is needed to demonstrate the effectiveness of the described behaviors.

The jerking and leg sweeping behaviors exhibited by these females are unique and are seen only in this context. Cushing and Opell (in press) describe two distinct shaking behaviors in U. glomosus, one shown in response to disturbance and another shown during prey capture. Both shaking behaviors have unique elements and both differ from the jerking response shown when an insect or spiderling crawls on the eggsac chain. When spiders are disturbed by ventral contact they shake their webs by alternately flexing and extending their first, and, to a lesser extent, their second pairs of legs. This alternating flexing and extending is maintained for several seconds with no pauses between sequences. When a spider detects the struggling of a prey caught in the web, it alternately flexes and extends the third pair of legs and alternately lowers and raises its abdomen. This abrupt shaking sequence may be sporadic with pauses between occurrences or frequent with no pauses. The jerking behavior described in this study is probably initiated when vibrations of an insect crawling along the eggsacs is transferred directly by the eggsac to the spider's fourth legs or abdomen. The spider flexes all four pairs of legs and then suddenly extends them ("stilts"). This sequence occurs one to many times with pauses between occurrences.

\section{SUMMARY}

Female Uloborus glomosus spiders deposit silken eggsacs in a chain along a radius of their horizontal orb-webs. When disturbed, these spiders remain in position next to their eggsacs, showing no active escape or avoidance behaviors. In contrast, spiders without eggsacs jump from, move to the edge of, or shake their webs. This study shows that females with eggsacs exhibit behaviors that could protect the eggs against parasitoids and predators. When a parasitoid wasp, Arachnopteromalus dasys, was placed on an eggsac chain, females responded by jerking their webs. Some females subsequently turned and walked along the eggsac chains, sweeping the surfaces of the eggsacs with their long front legs. These behaviors are unique to females guarding eggsacs. Females responded in a similar manner when $U$. glomosus spiderlings instead of wasps were 
placed on the eggsac chains. There was no significant difference between the percentage of females responding to wasps and to spiderlings, nor was there a significant difference in the initial response time of females with wasps on their eggsacs and those with spiderlings.

\section{ACKNOWLEDGMENTS}

I am grateful to Gabrielle Roth for her help in data collection. Thanks also to Dr. Brent D. Opell for his helpful suggestions on an earlier draft of this manuscript. Thanks to Drs. Richard D. Fell, Thomas A. Jenssen, and David A. West for additional advice and input. This project was supported by two grants from Sigma $\mathrm{Xi}$ and matching funds from the Biology Department of V. P. I. and S. U.

\section{REFERENCES}

Austin, A. D. 1985. The function of spider egg sacs in relation to parasitoids and predators, with special reference to the Australian fauna. J. Nat. Hist. 19: 359-376.

Austin, A. D. 1988. Guarding behaviour, eggmass shape and the eggsac in Clubiona robusta L. Koch (Araneae: Clubionidae). In: Australian Arachnology. Austin, A. D. and Heather, N. W. editors. pp. 87-95. The Australian Entomological Society, Brisbane, Australia.

Cushing, P. E. 1988. A study of disturbance behaviors in Uloborus glomosus (Araneae; Uloboridae) as possible predator avoidance strategies. M. S. thesis, Virginia Polytechnic Institute and State University, Blacksburg, VA.

Cushing, P. E. AND Opell, B. D. In press. Disturbance behaviors in the spider Uloborus glomosus (Araneae, Uloboridae): possible predator avoidance strategies. Can. J. Zool.

EberhaRd, W. G. 1974. Maternal behavior in a South American Lyssomanes. Bull. Brit. Arachnol. Soc. 3: 51.

FINK, L. S. 1987. Green lynx spider egg sacs: sources of mortality and the function of female guarding (Araneae, Oxyopidae). J. Arachnol. 15: 231-239.

GertsCh, W. J. 1979. American spiders. 2nd ed. Van Nostrand Reinhold, New York.

Gordh, G. 1976. A new genus of Pteromalidae from Missouri, the type-species of which parasitizes Uloborus octonarius Muma (Hymenoptera: Chalcidoidea; Araneida: Uloboridae). J. Kans. Ent. Soc. 49: 100-104.

HoffMASTER, D. K. 1982. Predator avoidance behaviors of five species of Panamanian orb-weaving spiders (Araneae; Araneidae, Uloboridae). J. Arachnol. 10: 69-73.

Kaston, B. J. 1948. Spiders of Connecticut. Conn. State Geol. Nat. Hist. Surv. Bull. 70: 1-874.

Matlack, M. C. And Jennings, D. T. 1977. Cohabitation of female spiders 
guarding egg sacs. J. Kans. Ent. Soc. 50: 519-522.

OPELl, B. D. AND EBERHARD, W. G. 1984. Resting postures of orb-weaving uloborid spiders. J. Arachnol. 11: 369-376.

Patel, B. H. ANd Bradoo, B. L. 1981. The cocoon spinning behavior and maternal care in Uloborus ferokus Bradoo (Araneae: Uloboridae). Zool. Anz., Jena 207: 78-87. 

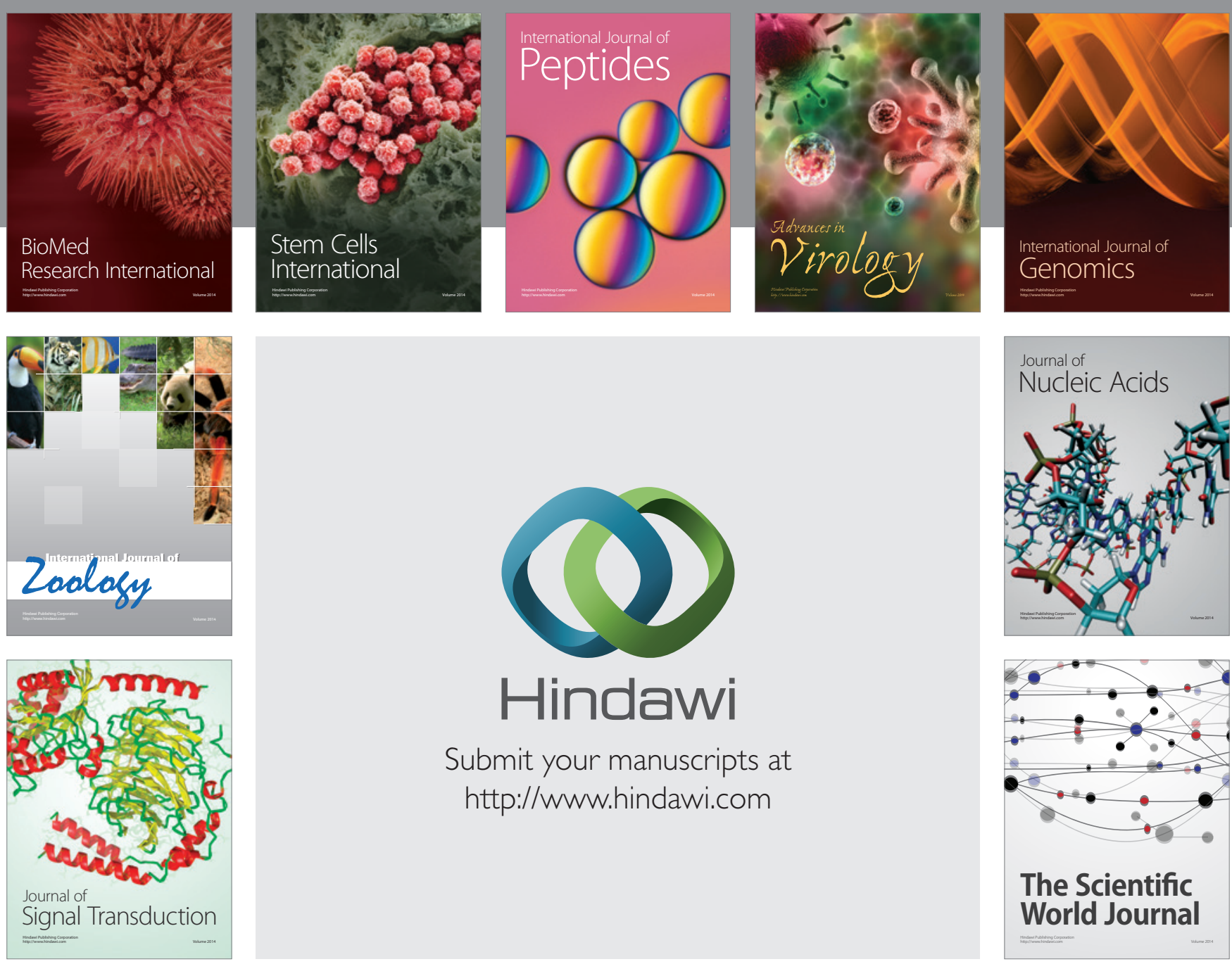

Submit your manuscripts at

http://www.hindawi.com
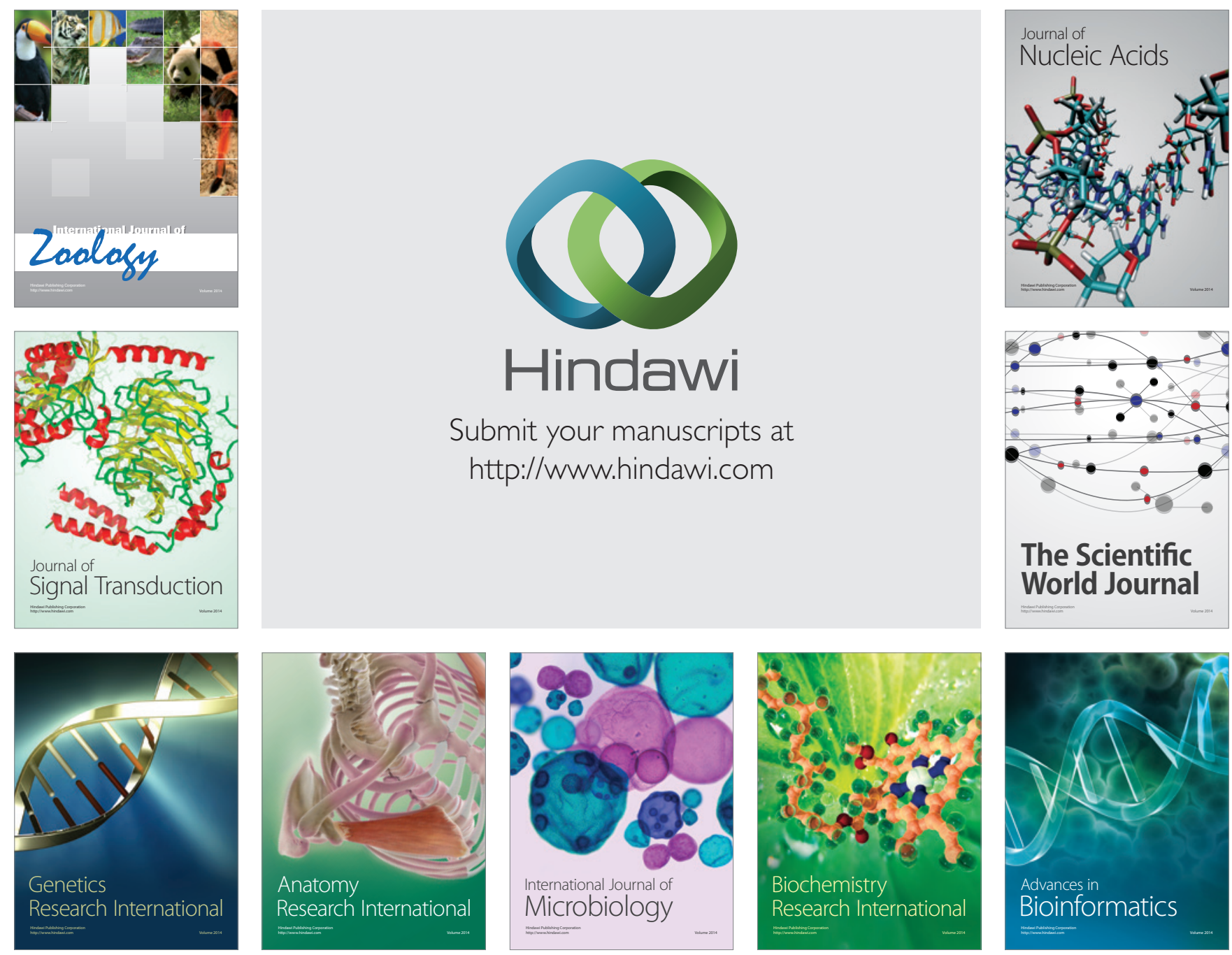

The Scientific World Journal
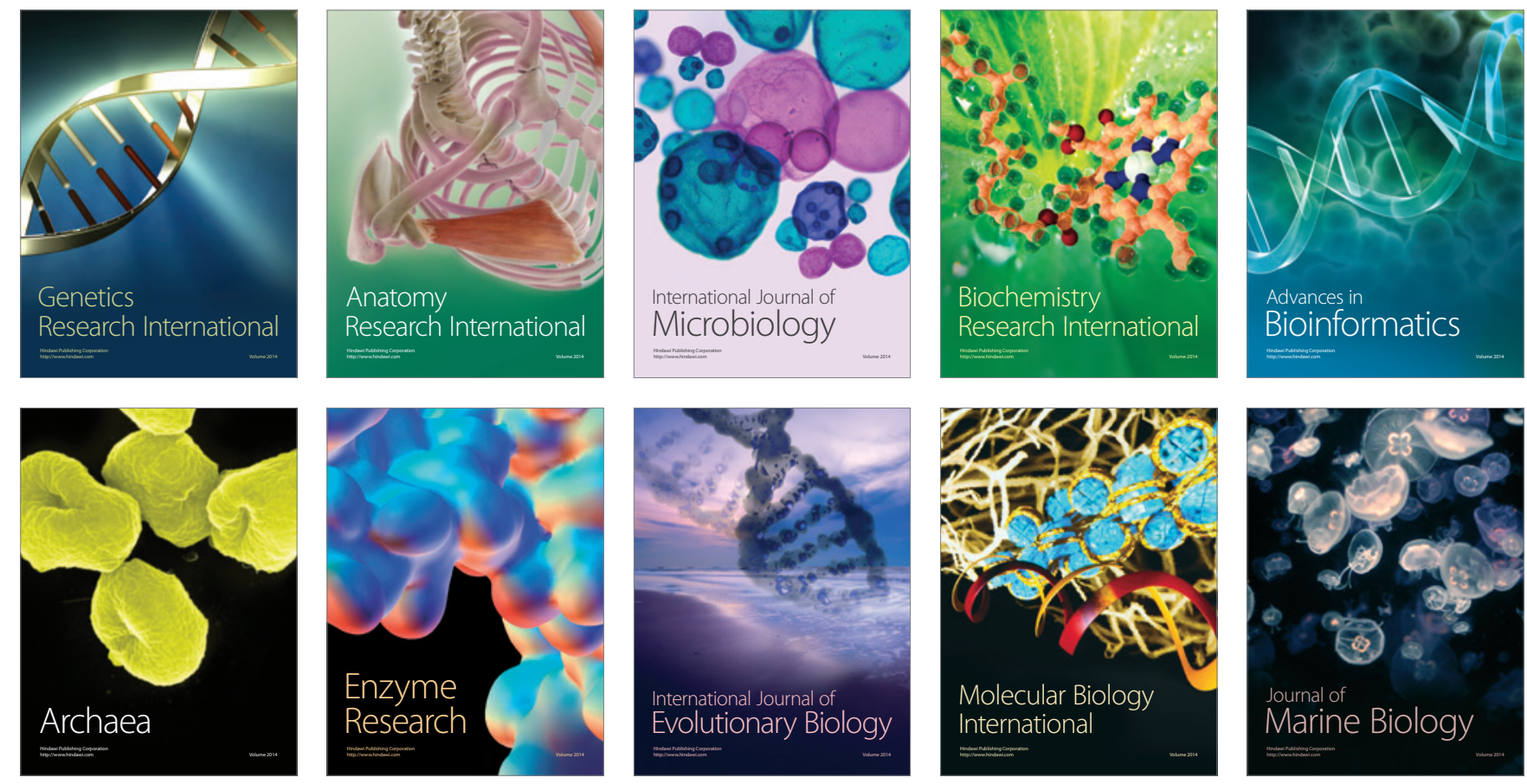